\title{
Bouveret's Syndrome: Management and Strategy of a Rare Cause of Gastric Outlet Obstruction
}

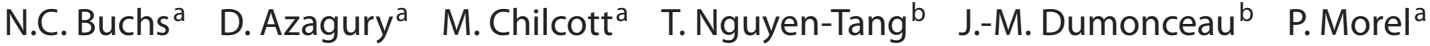 \\ ${ }^{a}$ Clinic for Visceral and Transplantation Surgery, Department of Surgery, and b Division of Gastroenterology, \\ Department of Internal Medicine, University Hospitals of Geneva, Geneva, Switzerland
}

Dear Sir,

Bouveret's syndrome is a subgroup (less than 1\%) of gallstone ileus in which a cholecystoduodenal fistula allows the passage of a stone that obstructs the duodenum and causes gastric outlet obstruction [1].

Since the first description by Léon Bouveret in 1896, fewer than 200 cases have been described in the worldwide literature [2].

Although there are little data about the outcome of Bouveret's syndrome, the mortality rate due to gallstone ileus was nearly $50 \%$, but in recent years has improved to about $15 \%$ [3]. This high mortality may be related to the advanced age of the typical patient as well as other comorbidities [4, 5]. The decrease in morbidity in recent years likely represents the impact of endoscopic treatment option in lieu of surgery as well as early diagnosis with non invasive imaging [4].

Thus, the importance of a correct preoperative diagnosis and management is the key in this rare pathology. We here report on a case of Bouveret's syndrome and propose an algorithm for the therapeutic strategy.

A 78-year-old man with unremarkable past medical history complained of loss of appetite, and sensation of early repletion for 3 weeks. Physical examination was unspecific with mild epigastric tenderness. Laboratory values revealed only mild leukocytosis (11 g/l) and increased gamma-
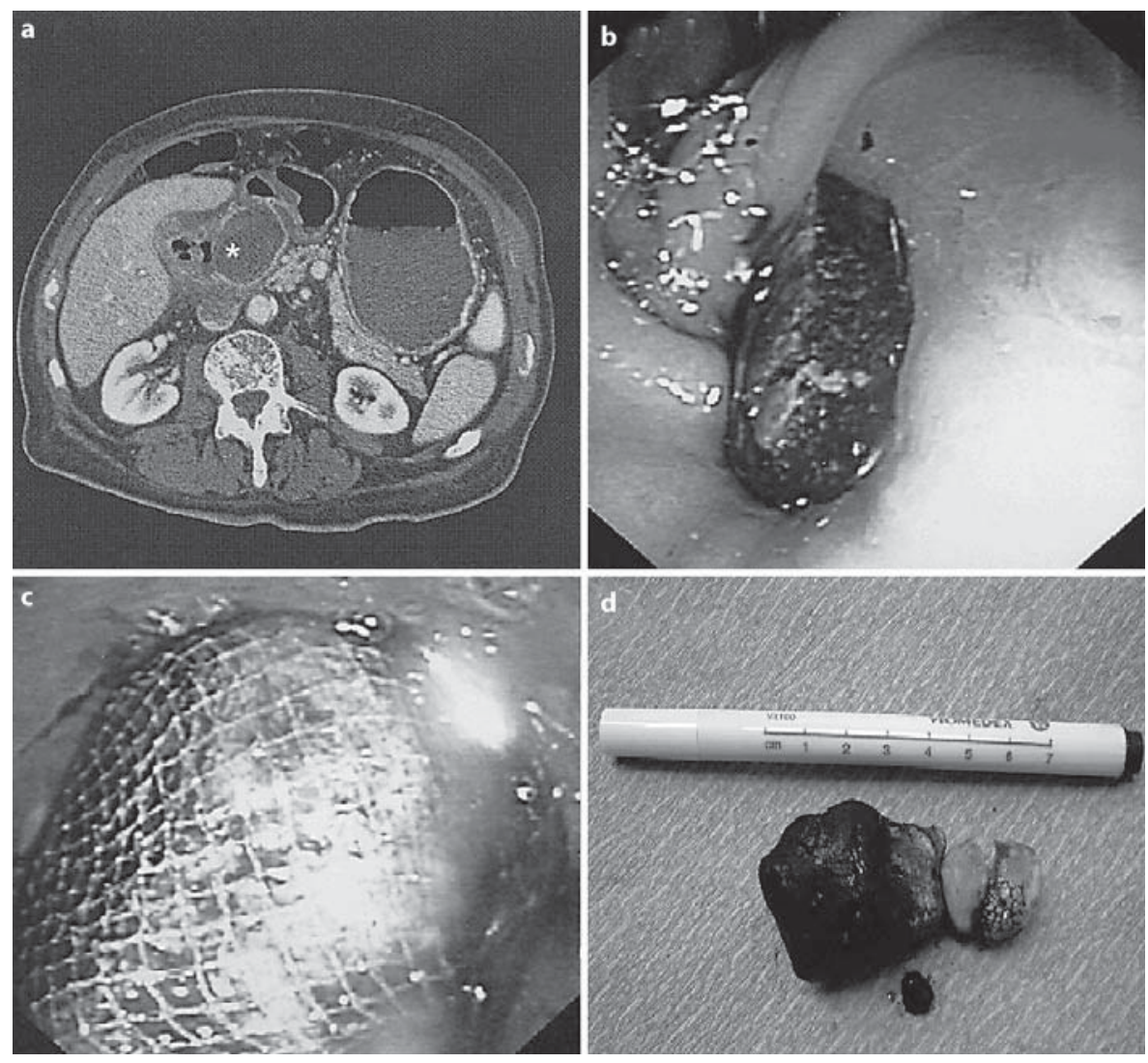

Fig. 1. a Computed tomography showing gastric outlet obstruction and an intraluminal lesion situated in the first duodenum $\left({ }^{*}\right)$, with air outside the gastrointestinal lumen. b A biliary stone protruding through the pylorus. c Attempt to endoscopically catch the stone without success. $\mathbf{d}$ The biliary stones after extraction.

\section{KARGER}

Fax +41613061234 E-Mail karger@karger.ch www.karger.com
(C) 2007 S. Karger AG, Basel 0012-2823/07/0751-0017\$23.50/0 www.karger.com/dig
Dr. Nicolas C. Buchs, MD

Clinic for Visceral and Transplantation Surgery, Department of Surgery

University Hospitals of Geneva, 24, rue Micheli-du-Crest

$\mathrm{CH}-1211$ Geneva 14 (Switzerland)

Tel. +41 22372 7698, Fax +4122372 7689, E-Mail nicolas.c.buchs@hcuge.ch 
Fig. 2. Algorithm of management of a suspicion of Bouveret's syndrome.

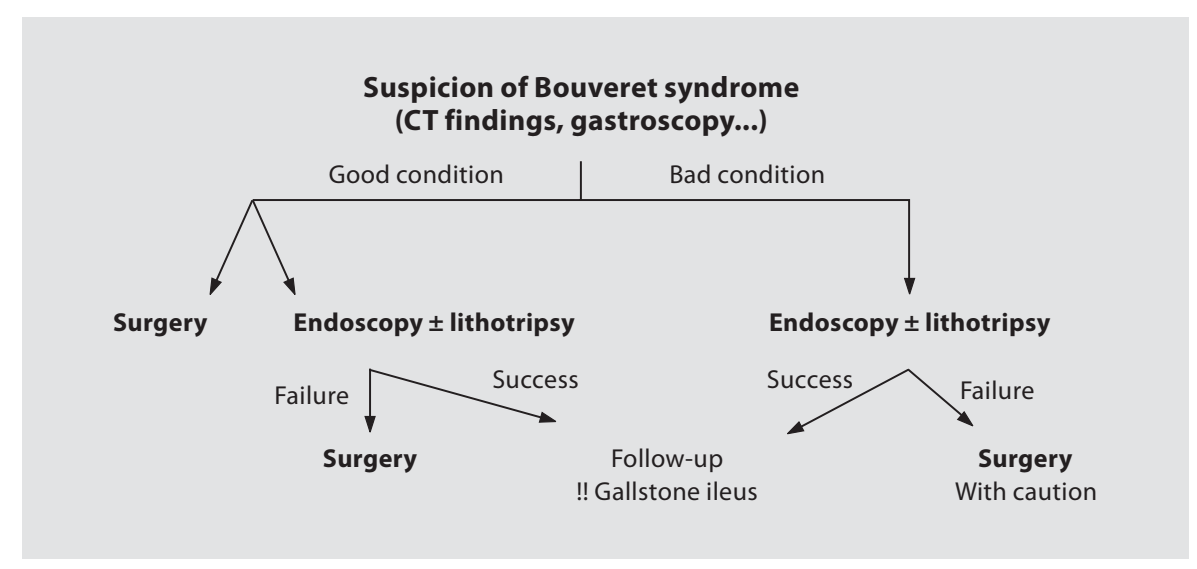

let obstruction in virtually all cases, but discloses the obstructing stone in only $69 \%$ of cases [8].

Therapeutic options available to remove the obstructive stone include:

- endoscopic stone retrieval after fragmentation (e.g. mechanical lithotripsy, extracorporeal shock-wave lithotripsy [9], dye-laser [10]);

- single- or double-staged surgery (i.e. stone removal associated with or followed by cholecystectomy and fistula repair $[2,7,8])$ by laparotomy or laparoscopy [11].

The advantages of a one-step surgical procedure are the avoidance of late complications (recurrent gallstone ileus, cholecystitis, cholangitis, and malignancy of the gallbladder). On the other hand, there are more early postoperative complications and a higher mortality rate when an extensive one-step procedure is performed $[2,12]$ as compared to a two-step procedure. Furthermore, reports indicate that biliary-enteric fistulas may close spontaneously after passage of the stone $[3,10]$, especially if the cystic duct is patent and residual gallstones are not present [12].

We propose an algorithm for the management of a suspicion of Bouveret's syndrome (fig. 2). The choice between an immediate surgery rather than an endoscopic procedure is based on the size of the stone, the availability of the exams, the hemodynamic conditions of the patient, and the patient's choice. When the stone is large and impacted, the risk of perforation with an endoscopic procedure exists [5, 13]. Furthermore, an endoscopic treatment does not correct the cholecystoduodenal fistula and could not examine for additional stones in the intestinal lumen distally [5]. Recently, Cappell et al. [8] reported a success rate of $60 \%$ with laser lithotripsy, but only of $25 \%$ for mechanical lithotripsy and 20\% for extracorporeal shock-wave lithotripsy. Surgery has a higher success rate (more than $80 \%$ ) [8].

In cases of patients with contraindication for surgery, an endoscopic procedure may be a good alternative, because of the low rate of complications. The fragments can be removed endoscopically or flushed to pass spontaneously through the intestine [10], but with the risk of a more distal gallstone ileus [13], necessitating a close follow-up. In cases of endoscopic failure, surgery becomes mandatory.

In conclusion, Bouveret's syndrome remains a rare cause of gastric outlet obstruction, but the management remains primordial to minimize the high mortality observed in this pathology. The treatment is based on endoscopy in feasible cases and surgery otherwise.

\section{References}

1 Masannat YA, Caplin S, Brown T: A rare complication of a common disease: Bouveret syndrome, a case report. World J Gastroenterol 2006;12:2620-2621.

2 Ariche A, Czeiger D, Gortzak Y, Shaked G, Shelef I, Levy I: Gastric outlet obstruction by gallstone: Bouveret syndrome. Scand J Gastroenterol 2000;35:781-783.

3 Clavien PA, Richon J, Burgan S, Rohner A: Gallstone ileus. Br J Surg 1990;77:737-742.

4 Brennan GB, Rosenberg RD, Arora S: Bouveret syndrome. Radiographics 2004;24: 1171-1175.

5 Liew V, Layani L, Speakman D: Bouveret's syndrome in Melbourne. Aust NZ J Surg 2002;72:161-163. struction, and an ectopic gallstone) [3-5, 7]. Upper GI endoscopy reveals gastric out- 
6 Geron N, Hazzan D, Shiloni E: Bouveret's syndrome as a rare complication of cholecystolithiasis: report of a case. Surg Today 2003; 33:66-68.

7 Marschall J, Hayton S: Bouveret's syndrome. Am J Surg 2004;187:547-548.

8 Cappell MS, Davis M: Characterization of Bouveret's syndrome: a comprehensive review of 128 cases. Am J Gastroenterol 2006; 101:2139-2146.
9 Dumonceau JM, Delhaye M, Deviere J, Baize M, Cremer M: Endoscopic treatment of gastric outlet obstruction caused by a gallstone (Bouveret's syndrome) after extracorporeal shock-wave lithotripsy. Endoscopy 1997;29: 319-321.

10 Maiss J, Hochberger J, Hahn EG, Lederer R, Schneider HT, Muehldorfer S: Successful laser lithotripsy in Bouveret's syndrome using a new frequency doubled double-pulse $\mathrm{Nd}$ : YAG laser (FREDDY). Scand J Gastroenterol 2004;39:791-794.
11 Malvaux P, Degolla R, De Saint-Hubert M, Farchakh E, Hauters P: Laparoscopic treatment of a gastric outlet obstruction caused by a gallstone (Bouveret's syndrome). Surg Endosc 2002;16:1108-1109.

12 Reisner RM, Cohen JR: Gallstone ileus: a review of 1001 reported cases. Am Surg 1994; 60:441-446.

13 Gencosmanoglu R, Inceoglu R, Baysal C, Akansel S, Tozun N: Bouveret's syndrome complicated by a distal gallstone ileus. World J Gastroenterol 2003;9:2873-2875. 